\title{
PERANCANGAN APLIKASI INVENTORY PADA CV.KOSMETIK INDAH CANTIK RAWAGENI DEPOK
}

\author{
Ahmad Pauji ${ }^{1}$, Triyadi ${ }^{2}$, Fredy A Sihombing ${ }^{3}$ \\ 1,2,3 Teknik Informatika, Fakultas Teknik dan Ilmu Komputer, Universitas Indraprasta PGRI \\ Jalan Raya No 80, Kelurahan Gedong, Pasar Rebo, Jakarta Timur \\ 1apauji56@gmail.com, ${ }^{2}$ triyadi170@gmail.com, ${ }^{3}$ fredyindraprasta.pgri@gmail.com
}

\begin{abstract}
ABSTRAK
Pertumbuhan sistem inventory bersamaan dengan kemajuan dikala ini begitu kilat serta ketat dalam melaksanakan persaingan bisnis, spesialnya dalam melaksanakan persediaan barang sehingga bisa penuhi permintaan pelanggan semakasimal mungkin. CV. Kosmetik Indah Cantik mengawali kiprahnya didunia kecantikan spesialnya dibidang kosmetik. Sistem berjalan yang dialami perusahaan sampai dikala ini merupakan belum terkomputerisasi dengan baik serta belum mempunyai sistem komputer yang terintegrasi. Permasalahan yang dirasakan CV. Kosmetik Indah Cantik ialah pada sistem pencatatan yang masih memakai manual, sehingga menjadikan tidak efektifnya dalam melaksanakan proses bisnis yang terdapat di CV. Kosmetik Indah Cantik. Tujuan dari riset ini merupakan guna mengenali sistem persediaan barang yang tengah berjalan pada CV. Kosmetik Indah Cantik. Mengenali persediaan barang supaya bisa membagikan informasi yang pas serta akurat. Membangun aplikasi yang ada fitur persediaan barang guna memudahkan user dalam menggunakanya. Tata cara riset yang digunakan merupakan grounded research serta Paradigma Siklus Hidup Klasik" Model Air Terjun". Riset ini menciptakan suatu aplikasi sistem informasi inventory dengan bahasa pemrograman Java, Netbeans 8. 2, XAMPP, dan database MySQL.
\end{abstract}

Kata Kunci: Sistem Informasi, Inventory, Java, Mysql

\begin{abstract}
The growth of the inventory system along with the current progress is very fast and tight in conducting business competition, especially in carrying out inventory of goods so that it can meet customer demand as much as possible. CV. Kosmetik Indah Cantik started her career in the world of beauty, especially in the field of cosmetics. The running system experienced by the company so far is not yet well computerized and does not yet have an integrated computer system. The problems felt by CV. Kosmetik Indah Cantik is a recording system that still uses manuals, thus making it ineffective in carrying out business processes contained in CV. Kosmetik Indah Cantik. The purpose of this research is to identify the inventory system that is currently running on CV. Kosmetik Indah Cantik. Identify inventory so that you can share information that is appropriate and accurate. Build an application that has an inventory feature to make it easier for users to use it. The research procedure used is grounded research and the Classical Life Cycle Paradigm "Waterfall Model". This research creates an inventory information system application using the Java programming language, Netbeans 8. 2, XAMPP, and MySQL database
\end{abstract}

Key Word: Information System, Inventory, Java, Mysql

\section{PENDAHULUAN}

Pertumbuhan sistem Inventory bersamaan dengan kemajuan saat ini begitu cepat. Jumlah perusahaan terus menjadi banyak serta terus melaksanakan usaha, serta strategi dalam mempertahankan bisnisnya. Kesuksesan perusahaan dalam mempertahankan bisnisnya tidak terlepas dari peran perusahaan tersebut dalam mengelola persediaan barang sehingga dapat pmemenuhi permintaan pelanggan semaksimal mungkin.

CV. Kosmetik Indah Cantik ialah sesuatu perusahaan yang mengawali kiprahnya di bidang kecantikan khususnya kosmetik, sistem berjalan yang dialami perusahaan merupakan belum memilikinya sistem komputer yang terintegerasi serta informasi olahan tersebut masih tersimpan dalam tiaptiap komputer belum mempunyai database server.

Menurut Moekijat dalam Prasojo (2011:152) memaparkan jika sistem merupakan setiap suatu terdiri dari objek, ataupun unsur, ataupun komponen yang bertata kaitan serta bertata ikatan satu sama lain, sedemikian rupa sehingga unsur tersebut ialah satu kesatuan pemrosesan ataupun pengolahan yang tertentu. 
Menurut Azhar Susanto, (2013 : 22) dalam bukunya yang berjudul Sistem Informasi Akuntansi : "Sistem adalah kumpulan atau group dari sub sistem/bagian/komponen apapun baik phisik ataupun non phisik yang saling berhubungan satu sama lain dan bekerja sama secara harmonis untuk mencapai satu tujuan tertentu"

Sesuatu sistem mempunyai ciri ataupun sifatsifat tertentu, antara lain mempunyai Komponen, Boundary (Batas Sistem), Environment (Area Luar Sistem), Interface (Penghubung Sisem), Input (Masukan), Output (Keluaran). Proses, Objective dan Goal (Target serta Tujuan Sistem) Hutahaean (2015)

Merupakan wujud jamak dari wujud tunggal informasi ataupun informasi item. Menurut Yakub (2015 : 5) informasi merupakan deskripsi realitas yang menggambarkan terdapatnya sesuatu peristiwa (event), informasi terdiri dari kenyataan (fact) serta angka yang secara relatif tidak berarti untuk pemakai. Informasi dapat berupa nilai yang terformat, text, citra, audio serta video.

Menurut Sutabri (2012: 1) menjekaskan kalau data merupakan informasi yang sudah diproses ke dalam suatu wujud yang memiliki makna untuk bagi si penerima dan mempunyai nilai nyata dan terasa untuk keputusan dikala itu ataupun keputusan mendatang. Menurut Sutarman (2012: 14) data merupakan sekumpulan fakta(informasi) yang diorganisasikan dengan tertentu sehingga mereka memiliki makna untuk sang penerima.

Menurut Mustakini (2009: 37) kalau ada 3 tipe kualitas data, antara lain: Accurate, Timeliness, Relevance. Menurut Venia Agnes Tananjaya (2012) menjelaskan bahwa kualitas sistem informasi ialah kualitas suatu produk atau pelayanan yang pada biasanya diukur menurut kecocokan pemakai dengan sistem informasi tersebut, dimana sistem informasi mampu diaplikasikan sesuai dengan apa yang diinginkan oleh pemakai.

Persediaan merupakan sesuatu aktivas yang meliputi beberapa barang milik perusahaan dengan maksud guna dipasarkan dalam satu periode yang normal, yang disediakan guna penuhi permintaan dari konsumen. Persediaan bisa dimaksimalkan dengan mengadakan perencanaan serta pengorganisasian yang lebih efektif, sehingga produktivitas dari perusahaan senantiasa terpelihara kesinambungannya.

Menurut Handoko (2015) persediaan barang (Inventory) merupakan sesuatu sebutan universal yang membuktikan seluruh suatu ataupun sumber daya- sumber daya organisasi yang ditaruh dalam antisipasinya terhadap pemenuhan permintaan. Bisa disimpulkan kalau sumber energi bisa ditaruh guna mengestimasi terdapatnya permintaan yang besar dari konsumen.

Penelitian yang mendasari pada penelitian ini bersumber dari Rizki Fadilah (2021), dengan judul Perancangan Sistem Informasi Stock Barang Pada CV. Delta Vision Mandiri. Pada hasil riset ini diperoleh bahwa guna mengenali sistem informasi stok barang yang tengah berjalan pada CV Delta Vision Mandiri selaku bahan pertimbangan dalam melaksanakan pengembangan sistem yang hendak dilakukan, guna meningkatkan sistem aplikasi stok barang pada CV Delta Vision Mandiri. Berdasarkan hal tersebut, penulis tertarik untuk melakukan penelitian yang serupa dengan tujuan untuk merancang aplikasi sistem persediaan barang pada CV. Kosmetik Indah Cantik.

\section{METODE PENELITIAN}

Riset ini memakai metode grounded research serta Paradigma Siklus Hidup Klasik" Model Air Terjun" Menurut Pressman (2012) Model Waterfall (model air terjun) merupakan suatu model pengembangan secara sekuensial. Paradigma siklus hidup klasik untuk pengembangan sistem diilustrasikan seperti pada gambar berikut :

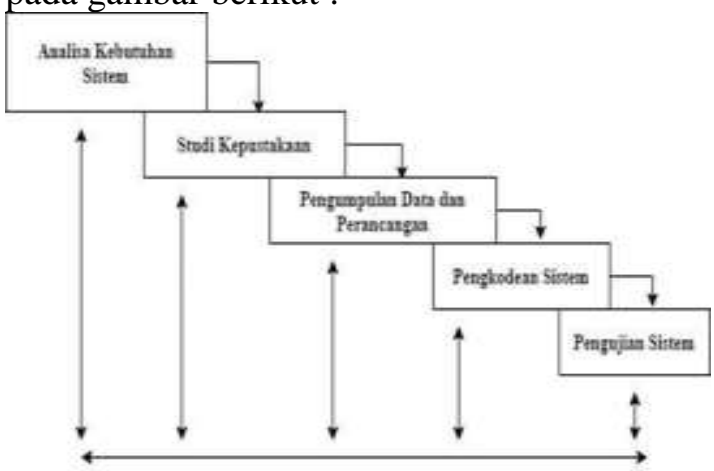

Gambar 1 : Paradigma Siklus Hidup Klasik "Model Air Terjun" 
Berikut uraian kegiatan dalam langkahlangkah pengembangan sistem inventory pada CV. Kosmetik Indah Cantik ialah:

\section{A. Analisa Kebutuhan Sistem}

sesi ini, sistem hendak dianalisis bagaimana hendak dijalankan nantinya, hasil analisis berbentuk kelebihan serta kekurangan sistem, peranan sistem, sampai pembaharuan yang bisa diterapkan.

\section{B. Studi Kepustakaan}

Penulis melaksanakan studi kepustakaan bersumber pada rujukan serta bermacam dialog ulasan baik dengan dosen pembimbing ataupun orang yang berkompeten pada permasalahan ini. Studi kepustakaan bertujuan guna menekuni serta menguasai dasar teori yang berhubungan dengan analisa kebutuhan yang telah dilakukan.

C. Pengumpulan Data dan Perancangan Sistem

sistem bertujuan guna merancang sistem yang hendak terbuat supaya sanggup diimplementasikan dengan kebutuhan pengguna.

D. Pengkodean Sistem

adalah proses menterjemahkan dokumen hasil desain menjadi baris- baris perintah bahasa pemrograman. Semakin baik hasil analisis serta desain yang dicoba, maka proses pengkodean ini lebih mudah dilakukan.

\section{E. Pengujian Sistem}

Sebelum sistem informasi inventori digunakan dengan baik, wajib dilakukan pengujian terlebih dulu. Rangkaian penguji ini dijalankan bersama- sama dengan data aktual dari sistem yang sudah ada atau sistem yang tengah berjalan.

\section{HASIL DAN PEMBAHASAN}

Ketentuan sistem informasi inventory hendak yang diusulkan pada CV. Kosmetik Indah Cantik ialah sebagai berikut:

1. Pegawai selaku admin hendak login serta melaksanakan pengolahan informasi pada sistem

2. Perusahaan melakukan pemesanan, pembelian serta pembayaran barang ke supplier.

3. Supplier

hendak memberikan data supplier, informasi barang serta bukti pembayaran ke perusahaan.
4. Perusahaan hendak memberikan info data stok barang serta data transaksi harian ke pegawai.

5. Pegawai hendak menginfokan data stok barang serta harga barang ke perusahaan.

6. Pembeli melaksanakan pembelian barang serta melaksanakan pembayaran barang ke perusahaan.

7. Perusahaan hendak menginfokan harga barang serta memberikan bukti pembayaran kepada pembeli

8. Perusahaan hendak membagikan berkas laporan kegiatan barang masuk, barang keluar, transaksi serta stok barang ke Owner.

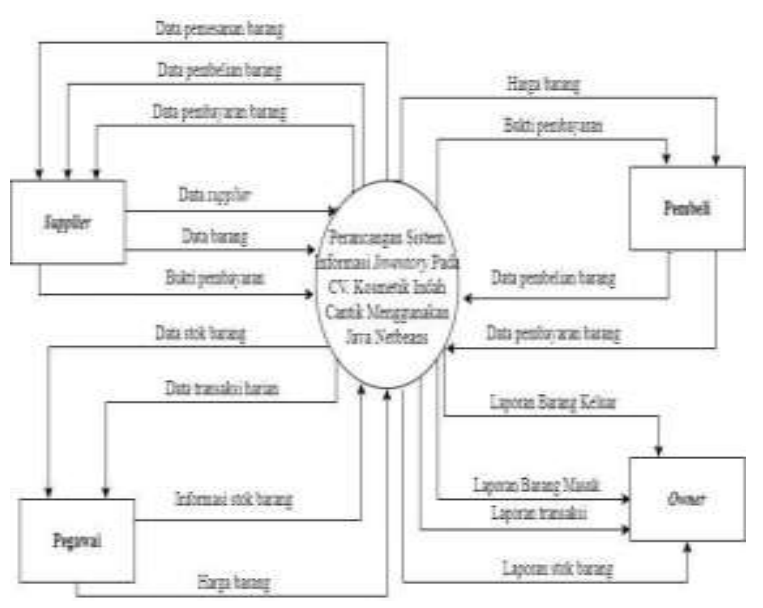

Gambar 2. Diagram Konteks Sistem yang Diusulkan

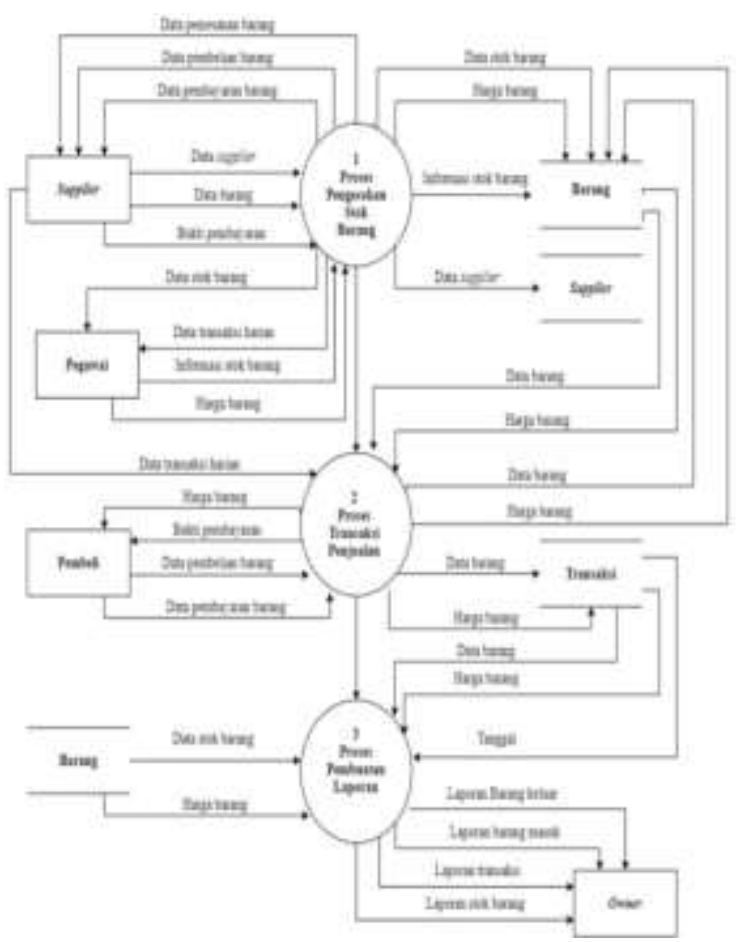

Gambar 3. Diagram Nol Sistem yang Diusulkan 


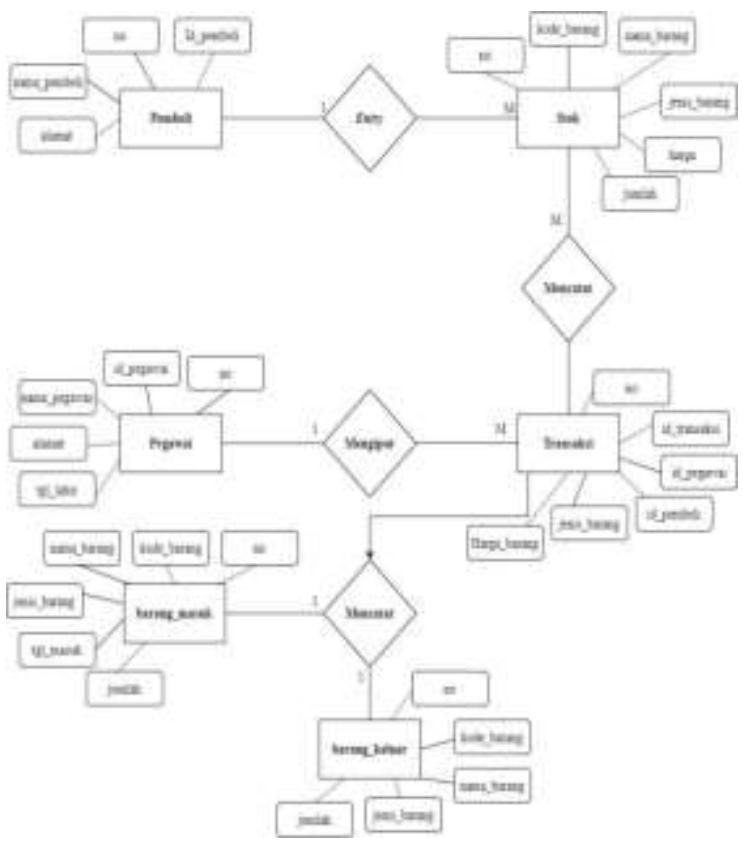

Gambar 4. Diagram ERD (Entity Relationship Diagram)

Selanjutnya penulis membuat aplikasi dengan menggunakan Java Netbeans berbasi desktop dan database MySQL. Berikut ini adalah tampilan dari aplikasi sistem informasi CV. Maestro:

\section{TAMPILAN LAYAR}

Tampilan Login

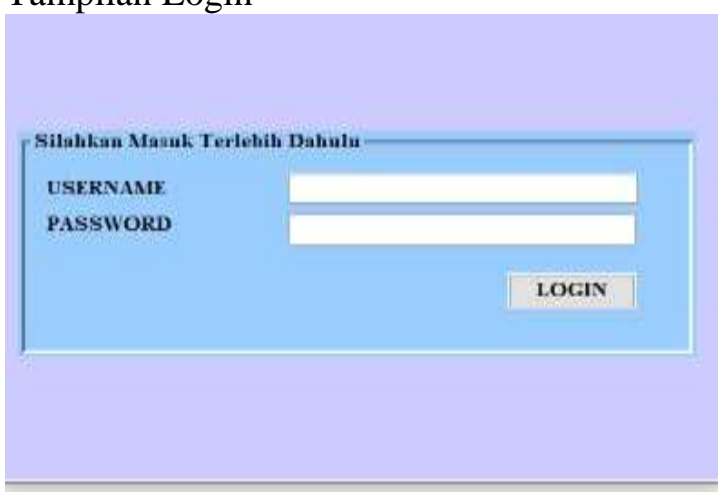

Gambar 5. Tampilan Menu Login

Tampilan ini terdapat pada awal program. Menu login digunakan sebagai kata kunci sebelum kita memasuki program utama. Agar tidak sembarang orang dapat mengakses program ini.
Tampilan Menu Utama

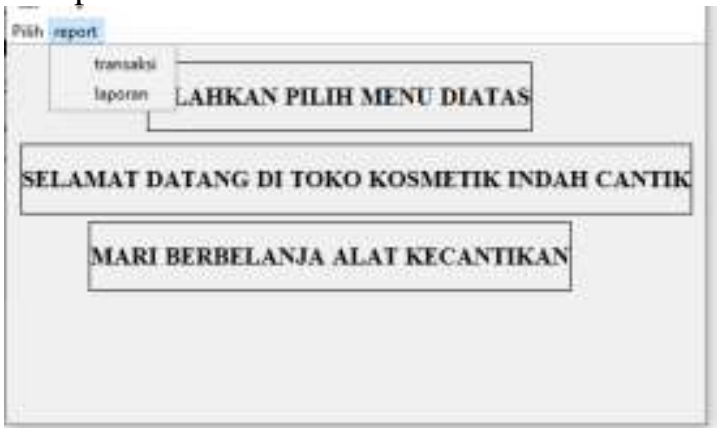

Gambar 6. Tampilan Menu Utama

Tampilan ini menampilkan menu sistem informasi inventory di CV. Kosmetik Indah Cantik. Pada menu utama tersedia menu menu master yang digunakan untuk memasukkan atau mencetak data yang berkaitan dengan kegiatan inventory.

Tampilan Input Data Karyawan

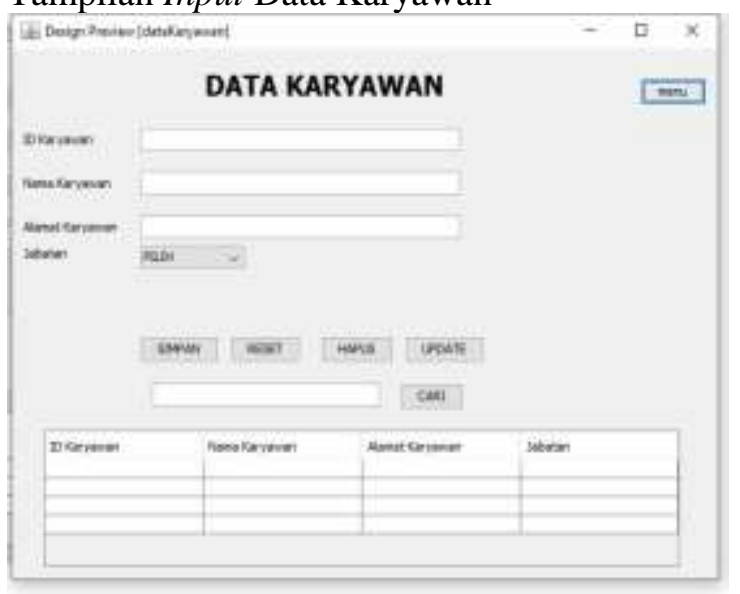

Gambar 7. Tampilan Menu Data Karyawan

Tampilan layar karyawan ini digunakan untuk peng-inputan-an datakaryawan yang bekerja pada CV.Kosmetik Indah Cantik.

Tampilan Input Data Pembeli

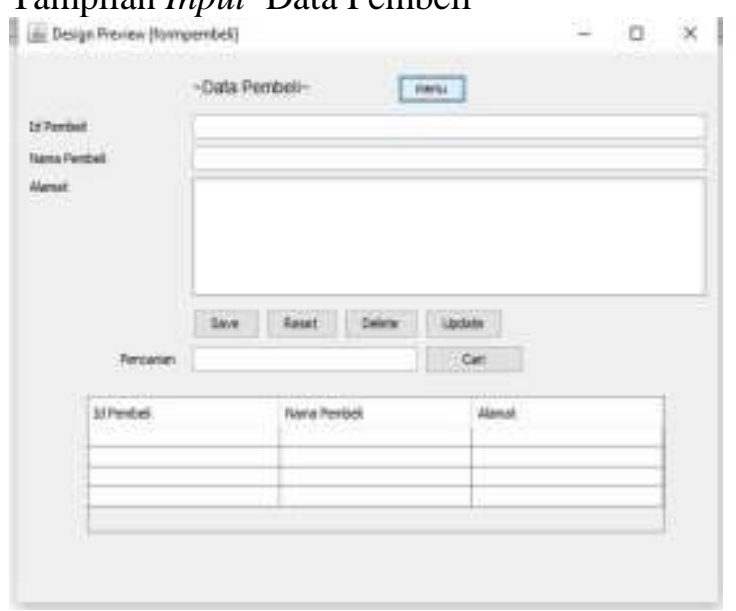

Gambar 8. Tampilan Menu Data Karyawan 
Tampilan pembeli ini digunakan untuk penginputan-an data pribadipembeli.

\section{Tampilan Input Data Barang}

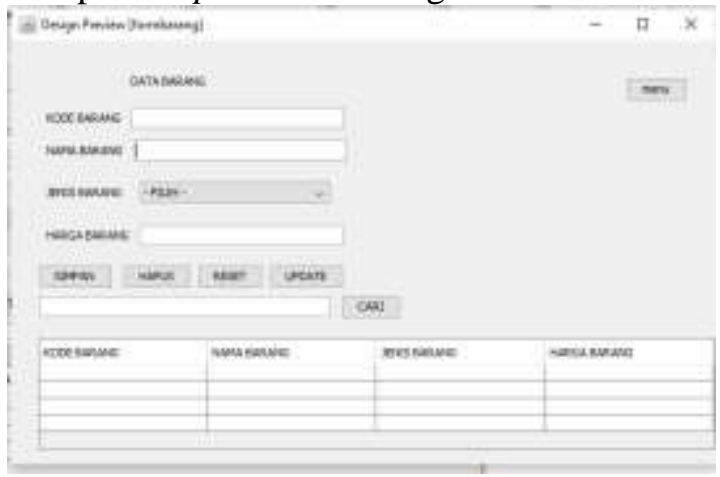

Gambar 9. Tampilan Data Barang

Tampilan ini merupakan rancangan tampilan Form data barang, menu ini digunakan untuk peng-inputan-an data barang.

Tampilan Input Form Barang Masuk

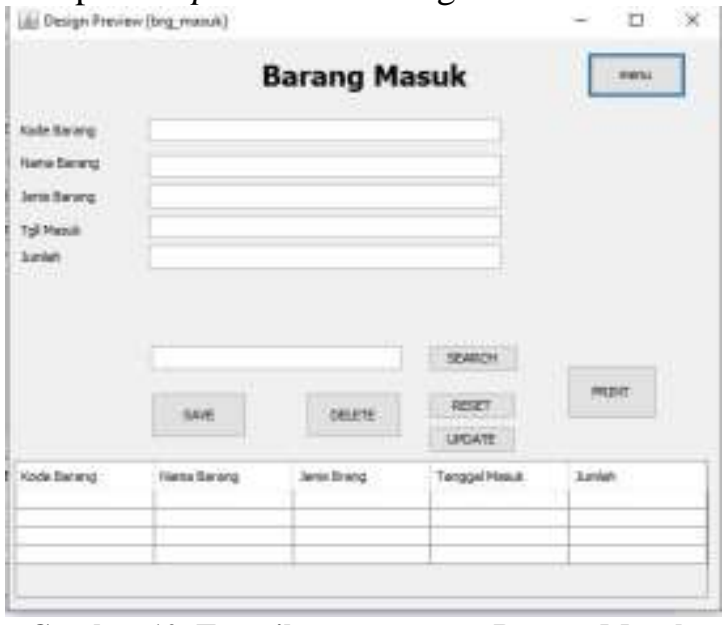

Gambar 10. Tampilan Input Form Barang Masuk

Merupakan tampilan data barang masuk yang ada di perusahan, menu ini digunakan untuk peng-input-an data yang baru masuk.

Tampilan Input Form Barang Keluar

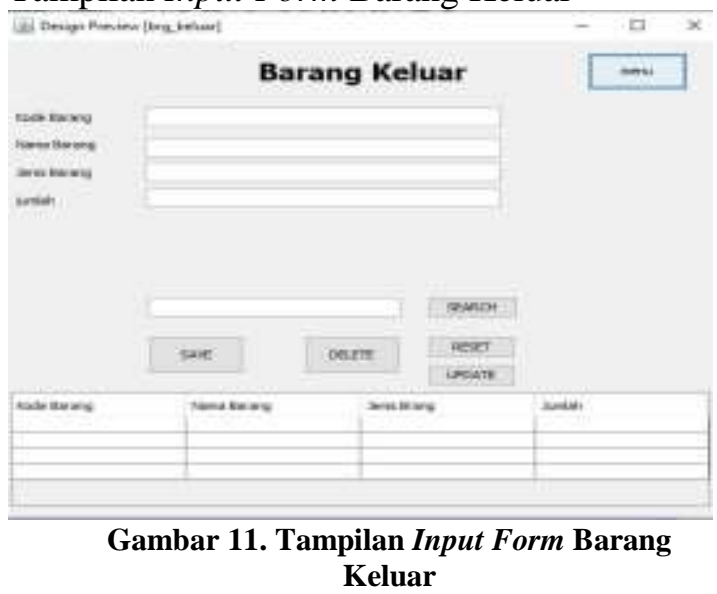

Merupakan tampilan data barang keluar, sesuai barang yang keluar gudang/ perusahaan, menu ini digunakan untuk pengecekan, peng- input-an dan updating data barang keluar.

Tampilan Input Form Transaksi

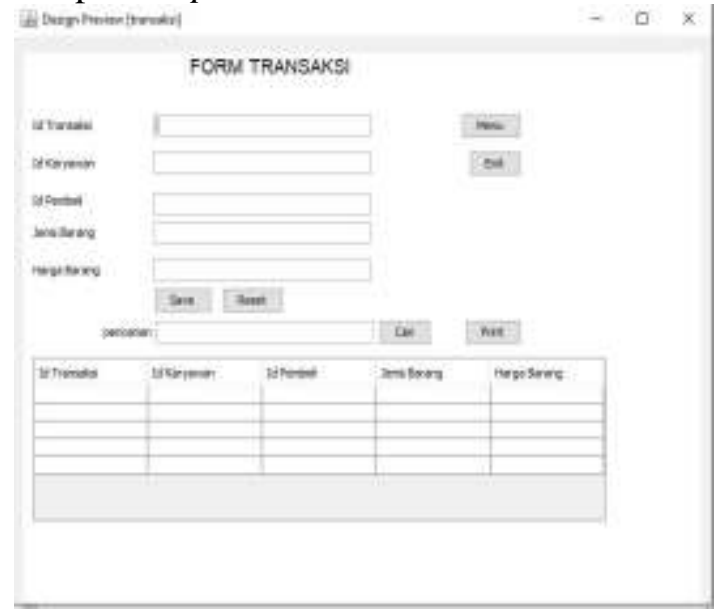

Gambar 12. Tampilan Input Form Transaksi

Merupakan tampilan data transaksi /penjualan yang di buka di CV. Kosmetik Indah Cantik, menu ini digunakan untuk pengecekan, peng-input-an dan updating data transaksi/penjualan

Tampilan Input Form Supplier

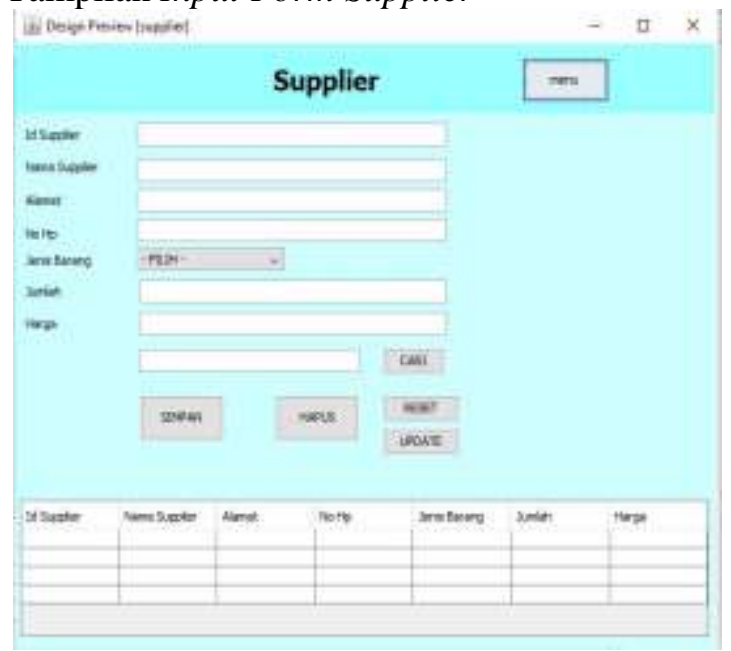

Gambar 13. Tampilan Input Form Supplier

Tampilan layar supplier ini digunakan untuk peng-inputan-an data perorangan pemasok stok barang pada CV.Kosmetik Indah Cantik 
Tampilan Output Stok Barang

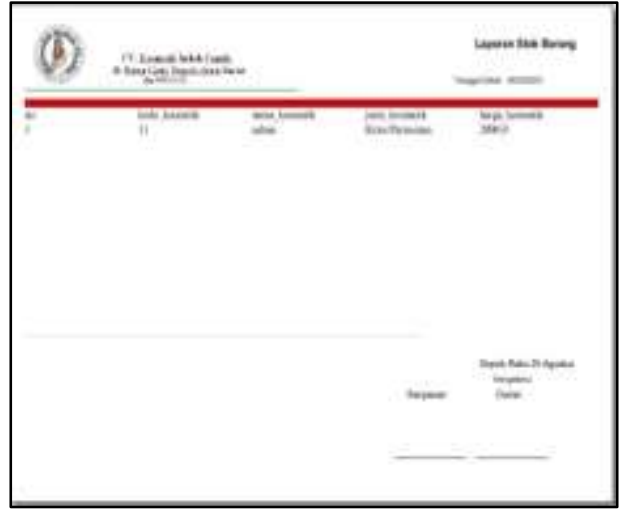

Gambar 14. Tampilan Output Stok Barang

Dalam laporan stok barang terdapat data barang yang tersisa

Tampilan Output Barang Masuk

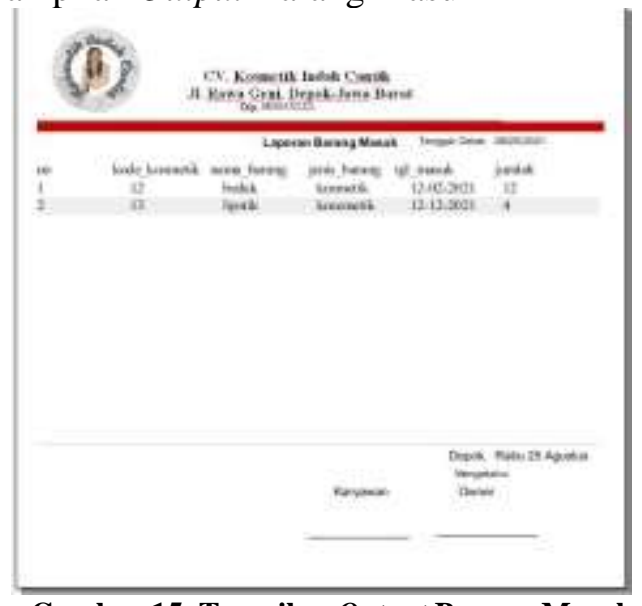

Gambar 15. Tampilan Output Barang Masuk

Dalam laporan data barang masuk terdapat informasi tentang data barang yang masuk

Tampilan Output Barang Keluar

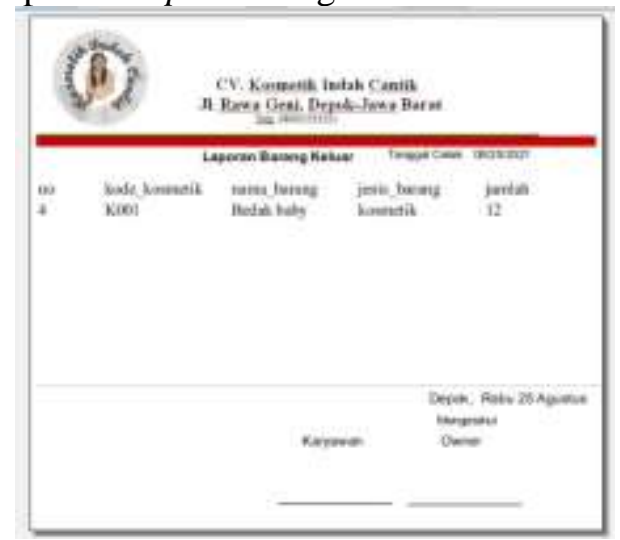

Gambar 16. Tampilan Output Barang Keluar Dalam laporan data barang keluar terdapat informasi tentang data barang yang keluar.
Tampilan Output Transaksi

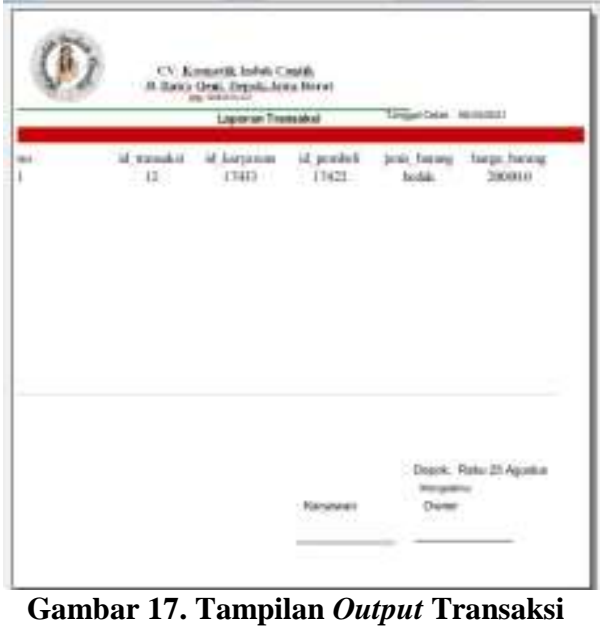

Dalam laporan data transaksi berisi tentang data penjualan perbulan atau pertahun.

\section{SIMPULAN DAN SARAN}

Program yang dibuat sanggup digunakan dengan baik serta sanggup guna mengambil alih proses pencatatan manual serta transfer data yang sebelumnya hanya menggunakan Microsoft Excel. Penggunaan program tidak bisa dilakukan oleh sembarang orang sebab dilengkapi dengan username dan password untuk memulai menjalankan aplikasi. Proses sistem informasi menjadi lebih akurat serta efektif dan penyajian laporan yang lebih terkordinasi sesuai kebutuhan yang diinginkan. Masukan yang bisa dipertimbangkan guna Sistem Informasi Inventory Pada tahapan pengembangan berikutnya, sanggup ditambahkan beberapa prosedur enkripsi informasi yang bermanfaat guna meningkatkan sistem keamanan pada aplikasi. Melaksanakan pelatihan pada user di CV. Kosmetik Indah Cantik agar bisa menguasai dalam menggunakan aplikasi ini

\section{DAFTAR PUSTAKA}

Fadilah, R. (2021). Perancangan Sistem Informasi Stok Barang pada CV Delta Vision Mandiri. Jurnal Riset Dan Aplikasi Mahasiswa Informatika (JRAMI), 2(02), 189-196. https://doi.org/10.30998/jrami.v2i02.77 6

Hutahaean, J. (2015). Konsep Sistem Informasi. Deepublish.

Ii, B. A. B., \& Teori, L. (2011). Handoko( 2015). 2004, 7-24.

Moekijat dalam Prasojo (2011:152). (2019). Moekijat dalam Prasojo (2011: 152). 
Journal of Chemical Information and Modeling, 53(9), 1689-1699.

Mustakini (2009: 37). (n.d.). Mustakini (2009:

37). https://ilearning.me/kkp-4/kkp-babii-3/teori-umum/konsep-dasarinformasi/

Nida Hanifah. (n.d.-a). Sutarman (2012: 14). Analisa Sistem Informasi Campus Service Iduhelp Berbasis Ilearning Pada Perguruan Tinggi Raharja. https://widuri.raharja.info/index.php?titl $\mathrm{e}=\mathrm{KP} 1011464440$

Nida Hanifah. (n.d.-b). Yakub (2012: 5). Analisa Sistem Informasi Campus Service Iduhelp Berbasis Ilearning Pada Perguruan Tinggi Raharja. https://widuri.raharja.info/index.php?titl $\mathrm{e}=\mathrm{KP} 1011464440$

Susanto, A. (2013). Azhar Susanto (2013:22). $11-44$.

https://elib.unikom.ac.id/files/disk1/700 /jbptunikompp-gdl-boykefitri-34970-7unikom_b-i.pdf

Sutabri (2012: 1). (n.d.). Sutabri (2012: 1). Analisa Sistem Informasi Campus Service Iduhelp Berbasis Ilearning Pada Perguruan Tinggi Raharja. https://widuri.raharja.info/index.php?titl $\mathrm{e}=\mathrm{KP} 1011464440$

Wati, R. P. (2015). Venia Agustines Tananjaya (2012). Pengaruh Kualitas Sistem Informasi, Perceived Usefulness, Dan Kualitas Informasi Terhadap Kepuasan Pengguna Sistem Informasi Akuntansi (Studi Pada PT Kereta Api Indonesia (Persero) Bandung), 1, 1670.

http://repository.unpas.ac.id/id/eprint/5 205\%0A 